\title{
Focus on Obesity
}

\section{Impact of maternal obesity on offspring obesity and cardiometabolic disease risk}

\author{
Amanda J Drake and Rebecca M Reynolds \\ Endocrinology Unit, Queen's Medical Research Institute, Centre for Cardiovascular Sciences, University of Edinburgh, \\ 47 Little France Crescent, Edinburgh, EH16 6TJ, UK
}

Correspondence should be addressed to R M Reynolds; Email: r.reynolds@ed.ac.uk

\begin{abstract}
The prevalence of obesity among pregnant women is increasing. In addition to the short-term complications of obesity during pregnancy in both mother and child, it is now recognised that maternal obesity has long-term adverse outcomes for the health of her offspring in later life. Evidence from both animal and human studies indicates that maternal obesity increases the risk for the offspring in developing obesity and altering body composition in child- and adulthood and, additionally, it also has an impact on the offspring's cardiometabolic health with dysregulation of metabolism including glucose/insulin homoeostasis, and development of hypertension and vascular dysfunction. Potential mechanisms include effects on the development and function of adipose tissue, pancreas, muscle, liver, the vasculature and the brain. Further studies are required to elucidate the mechanisms underpinning the programming of disease risk in the offspring as a consequence of maternal obesity. The ultimate aim is to identify potential targets, which may be amenable to prevention or early intervention in order to improve the health of this and future generations.

Reproduction (2010) $\mathbf{1 4 0} 387-398$
\end{abstract}

\section{Introduction}

The prevalence of obesity (defined as body mass index $(\mathrm{BMI})>30 \mathrm{~kg} / \mathrm{m}^{2}$ ) is increasing, even among women of childbearing age. A survey carried out in the USA between 2003 and 2006 reported that 32\% of women aged 20-44 years were classified as obese (WHO 2009). In the UK, the rise in obesity among pregnant women parallels the upward trend of obesity in the general population (Kanagalingam et al. 2005, Heslehurst et al. 2007). In addition to the short-term complications of obesity for both mother and child, emerging evidence suggests that maternal obesity has long-term detrimental consequences for offspring health.

One proposal to explain the link between maternal obesity and offspring obesity is the 'developmental overnutrition hypothesis'. This states that high maternal glucose, free fatty acid and amino acid concentrations result in permanent changes in appetite control, neuroendocrine functioning and/or energy metabolism in the developing foetus, thus leading to risk of adiposity (with accompanying risks of metabolic and

This paper is one of five papers that form part of a special Focus Issue section on Obesity. The Guest Editor for this section was J E Norman, Edinburgh, UK. cardiovascular disease) in later life (Armitage et al. 2008). There are now a number of animal studies supporting this hypothesis, and there is emerging evidence that a similar phenomenon occurs in humans. Here, we discuss the evidence from animal and human studies that maternal obesity has a permanent impact on offspring obesity and body composition as well as cardiometabolic health. In this developing field, much of the literature reports the phenotypic outcomes in the offspring, and more research is needed to dissect potential underlying mechanisms. Studies using animal models are attempting to separate the effects of maternal obesity per se from 'overnutrition', but this is harder to address in humans and is currently limited to those studies including reports of gestational weight gain. Likewise, in human studies, the challenge remains of disentangling the direct effects of maternal obesity on the developing child from the shared genetic and postnatal lifestyle influences.

\section{Timing of exposure}

In many early life programming paradigms, the timing of exposure is of critical importance in determining the offspring phenotype (Seckl 2001). In most rodent studies of maternal obesity, females are maintained on 
obesogenic diets (high fat and high carbohydrate or high fat alone) until they are significantly heavier than animals on a control diet and are maintained on the same diet through gestation (about 20-22 days). The offspring are then reared by their own mothers until weaning at around 3-4 weeks of age. Thus, in many studies, offspring have been exposed not only to maternal obesity but also to maternal overnutrition during both pregnancy and lactation, so that the effects of maternal obesity per se cannot be adequately separated from those of 'overnutrition'. While this may reflect the situation that occurs in humans, a number of studies do suggest that there may be particular developmental periods during which maternal obesity/overnutrition may have implications for offspring development. Recent data suggest that maternal obesity impairs oocyte quality in rodents and is associated with impaired development of the early embryo, so that programming effects in the offspring could occur as a consequence of maternal obesity even before fertilisation (Minge et al. 2008). Other studies have employed cross-fostering techniques in order to determine the importance of maternal overnutrition just during pregnancy on the programming of offspring obesity risk (Khan et al. 2005), while others suggest that maternal diet during both pregnancy and lactation is of particular importance in the programming of disease risk in the offspring (Bayol et al. 2008, Howie et al. 2009, Smith et al. 2009b). Finally, while for the purposes of this review, we have focussed on animal studies reporting programming effects in the offspring as a consequence of exposure to maternal obesity/high calorie diet during pregnancy alone or during both pregnancy and lactation, the critical importance of nutrition in the early postnatal period has also been demonstrated in a number of animal models. Thus, in rats, offspring exposed to early postnatal overnutrition as a consequence of suckling by mothers on a high-fat diet, as a result of artificial feeding with a high-carbohydrate diet or as a result of rearing in small litters are at increased risk of obesity and cardiometabolic disease (Plagemann et al. 1992, Khan et al. 2005, Srinivasan et al. 2008). Importantly, such effects are also noted in other species including non-human primates, for example overfeeding in the pre-weaning period increases adiposity in female baboons in young adulthood (Lewis et al. 1986).

Thus, data from animal studies suggest that there are various time points during early development, in which maternal obesity and/or maternal/foetal overnutrition may result in programming effects in the offspring. The relevance of these findings to humans remains to be clarified, although data discussed later in this review suggest that the effects of maternal obesity per se, i.e. the current body composition of the mother, may differ from those of excessive gestational weight gain, i.e. the consequences of the prevailing nutritional milieu during pregnancy, indicating that there are 'windows' for programming effects in the offspring.

\section{Programming of obesity and body composition}

\section{Evidence from animal studies for programming of obesity}

An increasing number of studies in rodents show that exposure to maternal obesity/overnutrition during both pregnancy and lactation is associated with the development of obesity in the offspring (Guo \& Jen 1995, Levin \& Govek 1998, Bayol et al. 2007, 2008, Samuelsson et al. 2008, Shankar et al. 2008, Liang et al. 2009, Nivoit et al. 2009, Tamashiro et al. 2009, Yan et al. 2010). This predisposition to obesity is amplified when offspring are themselves exposed to highly palatable or high-fat diets following weaning (Khan et al. 2003, 2004, Taylor et al. 2005, Bayol et al. 2007). In many of these studies, offspring have been studied after exposure to maternal obesity/overnutrition during both pregnancy and lactation, making it difficult to identify the important windows for the developmental programming of obesity. However, one study has shown that the offspring of rats rendered obese as a result of overfeeding before mating, but maintained on a standard diet during pregnancy, became obese in adulthood (Shankar et al. 2008). This suggests that maternal obesity at conception is associated with an increased risk of obesity in the offspring even with normal maternal dietary intake during pregnancy. The programming effects of intrauterine exposure to a high-fat diet in the absence of maternal obesity on offspring obesity risk have been investigated in several studies with variable results. For example, while White et al. (2009) reported that maternal obesity was necessary for the programming effects of a high-fat diet on offspring adiposity in a rat model, another study demonstrated that maternal pre-conceptual obesity had no effect over and above exposure to a high-fat diet during both pregnancy and lactation in terms of programming effects on adiposity (Howie et al. 2009). Likewise, exposure of females to a high calorie or a 'junk food' diet just from the start of pregnancy is associated with programming effects on offspring adiposity (Khan et al. 2005, Bayol et al. 2008). Programming effects as a consequence of overnutrition during pregnancy are also seen in animals with different reproductive strategies. In sheep, transient intake of propylene glycol (which is metabolised to glucose) in the last trimester of pregnancy results in lambs with increased weight and ponderal index at birth and more rapid postnatal growth than controls (Smith et al. 2009b).

\section{Evidence from animal studies for programmed changes in body composition}

In addition to the programming effects of maternal obesity on offspring obesity and fat mass, maternal obesity impacts on body composition. In rats, young offspring of mothers fed a junk food diet either during gestation alone or during both gestation and lactation 
exhibited increased intramuscular lipid content, semitendinosus muscle atrophy, altered expression of genes important in muscle growth and metabolism (Bayol et al. 2005) and reduced muscle force (Bayol et al. 2009). Such changes may be programmed early in development, as reduced myogenesis and increased intramuscular fat have also been reported in skeletal muscle of late gestation foetal sheep exposed to maternal obesity, in association with increased expression of inflammatory markers and altered AMP-activated protein kinase signalling (Zhu et al. 2008, Tong et al. 2009, Yan et al. 2010). These changes may play a role in altered muscle development and impact on later muscle size and strength. Additionally, increased intramuscular fat accumulation and altered gene expression may be important in the pathogenesis of insulin resistance in these models; indeed, offspring of obese mice demonstrate alterations in insulin signalling and mitochondrial complex activity in muscle in early adulthood (Shelley et al. 2009).

\section{What are the potential mechanisms underlying programmed changes in obesity?}

Studies have suggested a number of mechanisms that may underpin the programming effects of maternal obesity on offspring obesity risk, including programming of appetite and activity levels, programming of muscle structure and function and altered adipocyte biology.

Programming effects on the brain may be of particular importance in mediating the effects of maternal obesity on offspring appetite and activity. The offspring of mice maintained on a highly palatable diet during both pregnancy and lactation demonstrate hyperphagia before the development of obesity (Samuelsson et al. 2008), and rats exposed to a 'junk food' diet during both pregnancy and lactation themselves develop an exaggerated preference for fatty, sugary and salty foods when compared to control animals (Bayol et al. 2007). Such effects may reflect programmed changes in the hypothalamus, which has a pivotal role in the regulation of appetite and food intake (McMillen et al. 2005, Taylor \& Poston 2007). However, these studies have involved maternal exposure to high calorie diets during both pregnancy and lactation, since the impact of overfeeding in the early postnatal period in the programming of the hypothalamus is well known (e.g. Davidowa \& Plagemann 2000, Li et al. 2002). Detailed cross-fostering studies are therefore needed to determine the relative importance of the different developmental 'windows' for the programming of effects in the hypothalamus. Nevertheless, rodent studies using maternal exposure to a high-fat diet from weaning (Gupta et al. 2009) or solely during pregnancy (Chang et al. 2008) and one study in sheep in which glucose infusions were administered directly into foetuses (Muhlhausler et al. 2005) in later gestation have found altered expression of orexigenic peptides in the hypothalamus of foetuses, suggesting that prenatal exposure to increased nutrition may be sufficient to programme alterations in the brain which may impact on appetite control. Additionally, the risk of offspring obesity may be further exacerbated by reduced energy expenditure which has been observed in some, but not all, studies (Khan et al. 2003, Bayol et al. 2007, Samuelsson et al. 2008).

Exposure to maternal obesity may be associated with 'programmed' alterations in the expression of genes, which are important in adipocyte differentiation and function and which may be an additional mechanism underpinning the increased risk of obesity and insulin resistance in animal models. Alterations in adipose gene expression may be detected from early development, for example maternal obesity is associated with altered expression of genes in the adipose tissue of foetal sheep, including increased expression of lipoprotein lipase, adiponectin, leptin and the adipogenic factor peroxisome proliferator-activated receptor $\gamma$ (PPARG; Muhlhausler et al. 2007). Although the exact consequences of these alterations in gene expression remain to be explored, the authors speculate that they may reflect accelerated adipocyte differentiation, with a premature transition from a thermogenic to a lipid storage function (Muhlhausler et al. 2007). These changes may be persistent, since rodent studies suggest that maternal obesity is associated with changes in gene expression in adipose tissue in adulthood, including alterations in the expression of genes such as PPARG, $\beta$-adrenoceptors, insulin receptor substrate-1 (IRS1), vascular endothelial growth factor-A (VEGFA) and tumour necrosis factor $\alpha$ (TNF; Caluwaerts et al. 2007, Bayol et al. 2008, Samuelsson et al. 2008, Shankar et al. 2008). Thus, maternal obesity may be associated with programming of altered adipocyte proliferation and differentiation capacity (Bayol et al. 2008), increased expression of inflammatory mediators (Caluwaerts et al. 2007) and altered lipid turnover (Samuelsson et al. 2008, Shankar et al. 2008).

\section{Evidence from human studies}

\section{Maternal obesity and offspring obesity and body composition}

In humans, increased rates of obesity in mothers are paralleled by an increase in large for gestational age delivery rates (Surkan et al. 2004) and by an increase in obesity rates in children (Ogden et al. 2006). This, and the observation of early onset obesity even among children in the first 6 months of life (Kim et al. 2006), supports a relationship between maternal obesity and offspring obesity. Maternal obesity prior to pregnancy is associated with foetal macrosomia (Jensen et al. 2003), and there are a large number of studies linking increased 
birth weight with risk of overweight and obesity in childhood and adulthood (Parsons et al. 1999).

There are now several observational studies supporting an association between maternal obesity with increased risk of obesity in the offspring as neonates (Table 1), childhood (Table 2) and into early adulthood (Table 3). Where obesity in the offspring is assessed by BMI, studies show a clear relationship between increased maternal pre-pregnancy BMI and BMI during pregnancy with obesity in later life in the offspring (Laitinen et al. 2001, Whitaker 2004, Li et al. 2005, Reilly et al. 2005, Salsberry \& Reagan 2005, Lawlor et al. 2007, Koupil \& Toivanen 2008, Mesman et al. 2009, Reynolds et al. 2009, Stuebe et al. 2009, Tequeanes et al. 2009; Tables 2 and 3). In addition to increased BMI, there are also alterations in body composition of the offspring of obese mothers; maternal obesity is associated with increased fat mass, as assessed by calliper measurements of skinfold thickness or by dual X-ray absorptiometry, in neonates (Sewell et al. 2006, Harvey et al. 2007, Hull et al. 2008, Catalano et al. 2009, McIntyre et al. 2010; Table 1) and in children (Burdette et al. 2006, Blair et al. 2007, Gale et al. 2007; Table 2). Interestingly, offspring body fat does not appear to be associated with paternal fat mass (Shields et al. 2006). There is some evidence that the associations of maternal obesity with foetal growth may plateau at the highest levels of BMI (Mclntyre et al. 2010), suggesting that either a maximal influence is present, or alternatively, as maternal obesity can lead to offspring of both high and of low birth weight (Rajasingam et al. 2009), other factors that limit foetal growth may be operating. Intriguingly, the impact of maternal obesity on offspring obesity and body composition is maintained into adulthood, over and above current lifestyle factors with associations reported between maternal obesity and offspring BMI (Laitinen et al. 2001, Koupil \& Toivanen 2008, Reynolds et al. 2009, Stuebe et al. 2009, Tequeanes et al. 2009), and fat mass (Mingrone et al. 2008, Reynolds et al. 2009) up to the age of 31 years (Table 3).

\section{Maternal gestational weight gain and offspring obesity and body composition}

While, in humans, there are no studies specifically addressing components of the diet in the context of maternal 'overnutrition' and offspring outcome, gestational weight gain may reflect the exposure of the developing foetus to the prevailing nutritional environment and thus provide an opportunity to examine the influence of overnutrition as opposed to obesity per se. Interestingly, the impact of maternal obesity on risk of offspring obesity appears to be slightly different from the impact of excessive gestational weight gain. A number of studies have demonstrated a link between maternal gestational weight gain and later obesity in childhood (Oken et al. 2007, Olson et al. 2009) adolescence

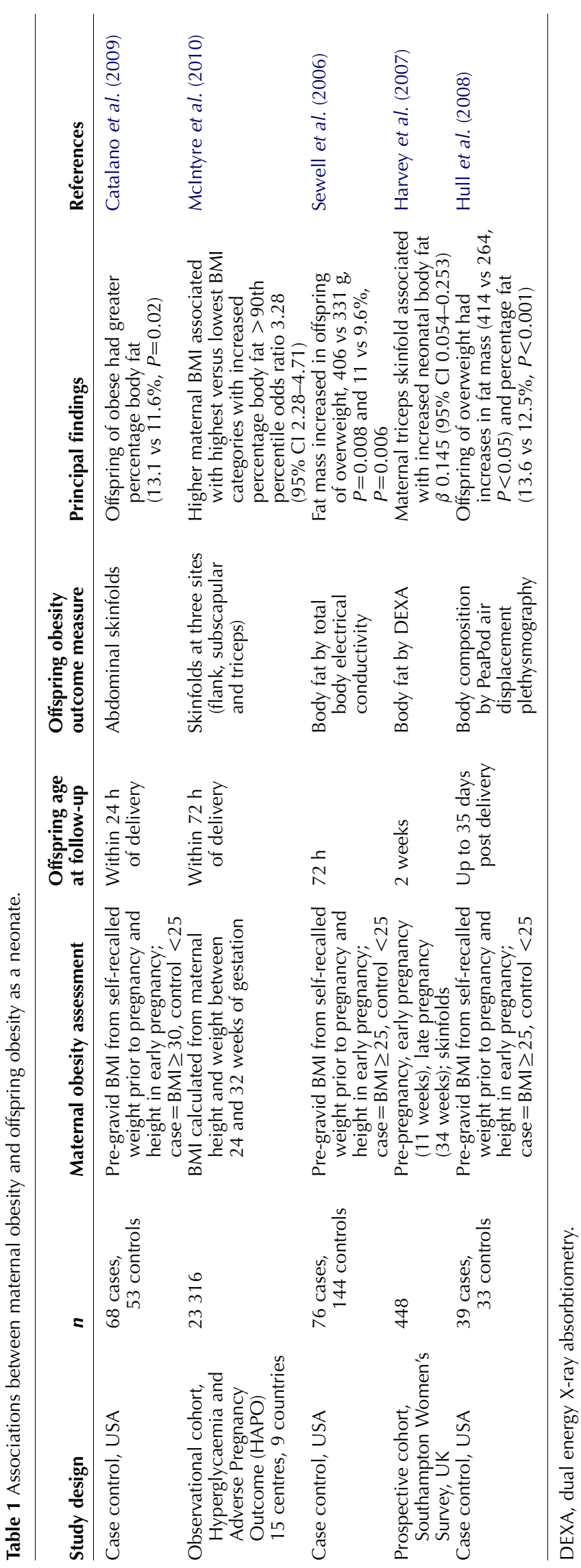

www.reproduction-online.org 


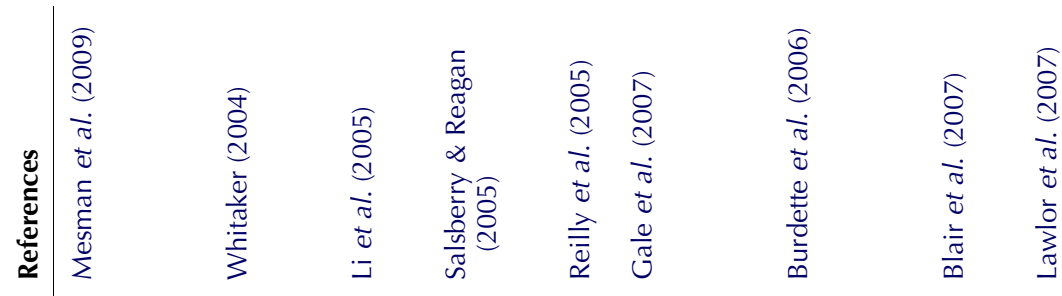

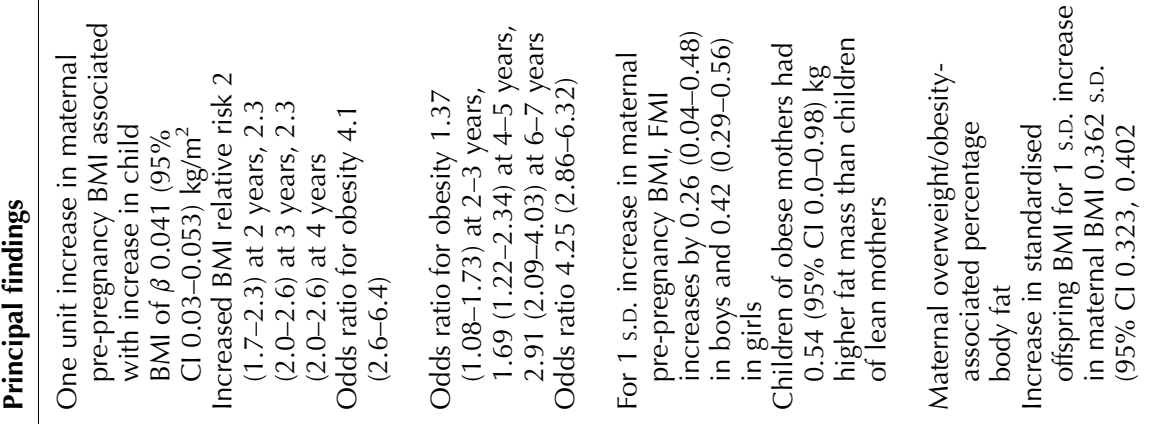

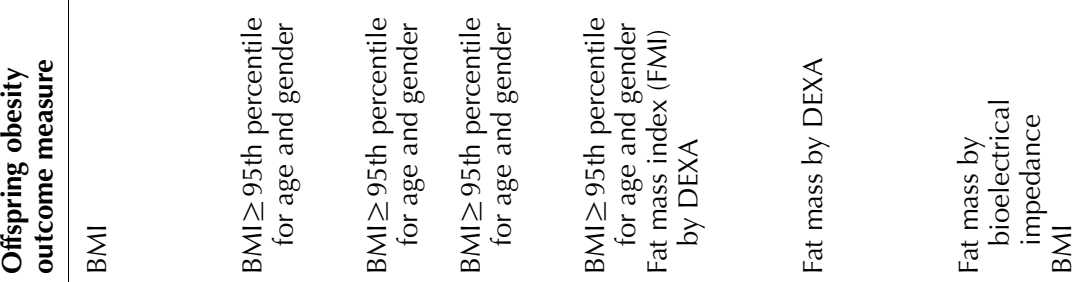

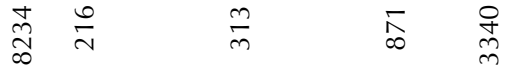
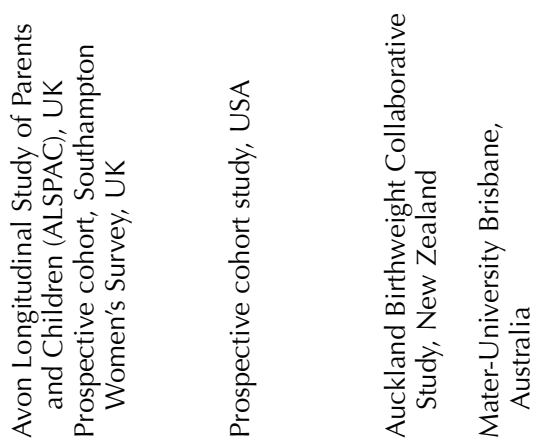


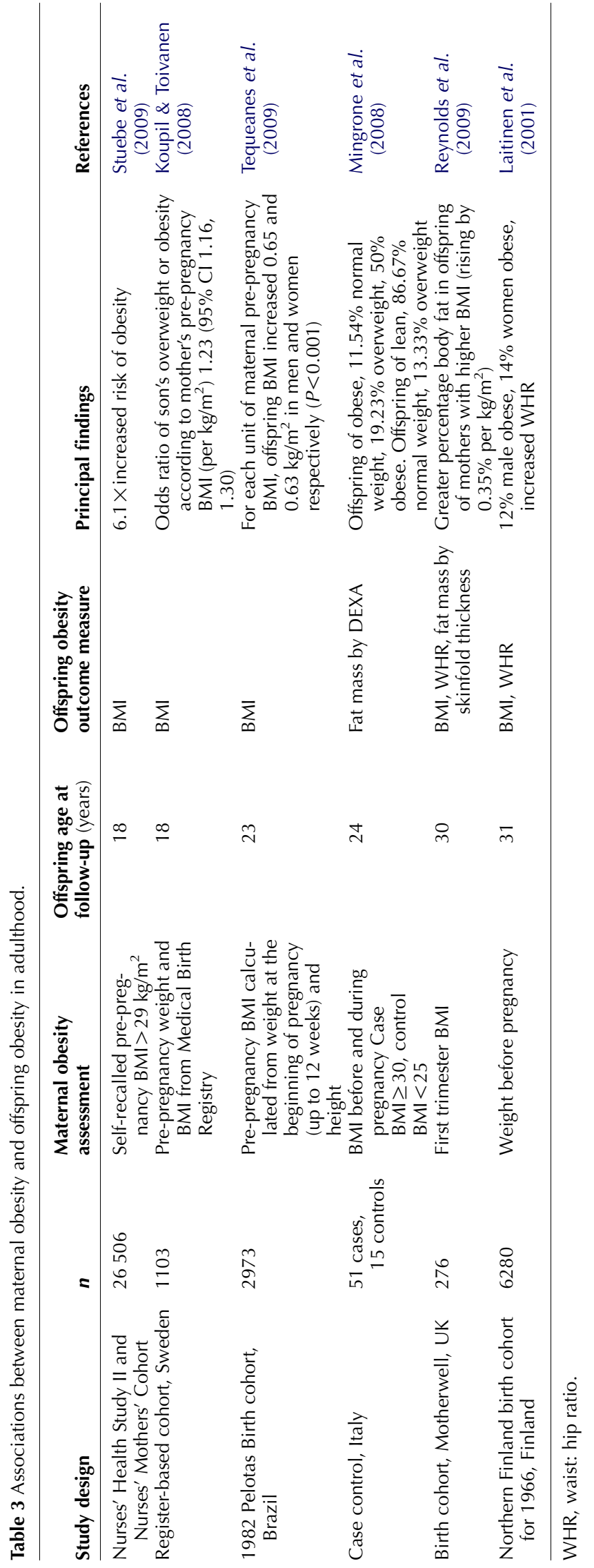

(Oken et al. 2008) and early adulthood (Mamun et al. 2009), while others have shown no effect (Catalano et al. 1995, Koupil \& Toivanen 2008). In these studies, the strength of the effect is generally less than that of maternal obesity per se, and there is some evidence that the effect is stronger among underweight/normal-weight women (Mamun et al. 2009). However, a recent study showed that the extremes of gestational weight gain were associated with obesity in the daughters at the age of 18 years (Stuebe et al. 2009) suggesting the importance of good maternal nutrition, even among women who are obese.

Interpretation of many of these studies is limited as pre-pregnancy $\mathrm{BMI}$ is often self-reported, and many studies do not have additional measurements of weight during pregnancy. Likewise, most studies do not have detailed measurements of maternal body composition during pregnancy, and so it is not possible to assess the impact of differing body fat distribution on the offspring. Most studies have not considered the potential confounding effect of breastfeeding, which may be important as obese women are less likely to initiate breastfeeding or may feed for a shorter time (Oddy et al. 2006). In addition, most studies have only considered obesity in the mother and have not tested the potential paternal contribution on offspring obesity (Lawlor et al. 2008).

\section{Programming of metabolism}

In addition to increasing the risk of offspring obesity, maternal obesity also impacts on offspring metabolism. To date, most studies have investigated effects on pancreatic function with attendant effects on glucose/insulin homoeostasis, but studies are beginning to examine the effects of maternal obesity on other components of the 'metabolic syndrome' including dyslipidaemia and non-alcoholic fatty liver disease.

\section{Glucose/insulin homoeostasis and pancreatic function}

In animal studies, exposure to maternal obesity/overnutrition during both pregnancy and lactation is associated with the development of metabolic dysfunction in offspring, including hyperinsulinaemia, hyperglycaemia and increased plasma levels of triglycerides, cholesterol and leptin, features that are amplified when offspring are themselves exposed to a high-fat diet (Guo \& Jen 1995, Bayol et al. 2008, Samuelsson et al. 2008, Shankar et al. 2008, Liang et al. 2009, Nivoit et al. 2009, Tamashiro et al. 2009, Yan et al. 2010). Additionally, there appears to be an age-related decline in glucose/insulin homoeostasis in many programming models; in mice, offspring of obese mothers were found to be hyperinsulinaemic at 3 months of age (young adulthood), but male offspring 
had developed frank diabetes with reduced plasma insulin and decreased pancreatic insulin content by 6 months of age (Samuelsson et al. 2008). It has been proposed that such an age-related decline in pancreatic function may be programmed at an early developmental stage; in sheep, maternal obesity is associated with increased foetal pancreatic weight and a marked increase in the number of insulin-positive cells per unit area of the foetal pancreas, perhaps reflecting enhanced early $\beta$-cell maturation (Ford et al. 2009). However, such changes in early pancreatic development may result in premature postnatal $\beta$-cell loss and result in a predisposition to the development of obesity and metabolic dysfunction in adulthood (Ford et al. 2009).

Recent studies in humans have started to examine the influence of maternal obesity on offspring glucose/insulin homoeostasis. In a small study, offspring of obese mothers (pre-pregnancy BMI $38.4 \mathrm{~kg} / \mathrm{m}^{2}$ ) were more insulin resistant (calculated umbilical cord glucose and insulin concentrations using the homoeostasis model) than offspring of lean mothers (pre-pregnancy BMI $22.0 \mathrm{~kg} / \mathrm{m}^{2}$; Catalano et al. 2009), suggesting that the foetus may have increased insulin secretion earlier in pregnancy (Carpenter et al. 1996). Recent evidence from the Hyperglycaemia and Adverse Pregnancy Outcome study including 23316 participants also reported an association between increased maternal BMI and foetal hyperinsulinaemia (assessed by cord serum C-peptide levels), even after adjustment for maternal glycaemia (Mclntyre et al. 2010). In the latter study, BMI in the mothers was measured in the third trimester of pregnancy, a measurement that is less closely correlated with maternal fat mass than BMI measured in early pregnancy (Sewell et al. 2007), and so this may have attenuated the findings.

There is some evidence that the effect of maternal obesity on insulin sensitivity persists into later life with offspring of overweight women (here defined as pregravid $\mathrm{BMI}>27.3 \mathrm{~kg} / \mathrm{m}^{2}$ ) having increased risk of developing the metabolic syndrome by age 11 years (Boney et al. 2005). One study investigated insulin sensitivity using a euglycaemic insulin clamp in 21 lean offspring aged 22 years of 'obese' parents compared with 23 lean offspring of normal-weight parents and found no significant differences between groups (Lazarin et al. 2004). However, the mothers were overweight (BMI $27 \mathrm{~kg} / \mathrm{m}^{2}$ ), rather than obese, and the study also included fathers who were obese. A more recent larger study examined 51 offspring in their early 20s of obese mothers (BMI $>30 \mathrm{~kg} / \mathrm{m}^{2}$ before and during pregnancy) and 15 offspring of normal-weight mothers (Mingrone et al. 2008). Insulin sensitivity was calculated from glucose and insulin results during an oral glucose tolerance test using the oral glucose insulin sensitivity index, and insulin secretion and $\beta$-cell glucose sensitivity were computed by a mathematical model. Of note, $69 \%$ of the obese group offspring were obese and 19\% were overweight. The offspring of the obese group were more insulin resistant, but $\beta$-cell glucose sensitivity did not differ between groups. In this study, the BMI of the fathers was similar in both groups. Overall, these findings suggest that maternal obesity impacts on offspring glucose homoeostasis, but also raises the potential importance of other nutrients in pregnancy regulated by insulin such as triglycerides, free fatty acids and amino acids which also regulate foetal growth (Schaefer-Graf et al. 2008).

\section{Non-alcoholic fatty liver disease}

There is increasing evidence that exposure to an adverse prenatal environment may predispose offspring to developing fatty liver, the hepatic manifestation of the metabolic syndrome (Magee et al. 2008). Offspring of female rats and mice exposed to a high-fat diet before conception and during pregnancy have increased liver triglyceride content (Buckley et al. 2005, Bruce et al. 2009, Elahi et al. 2009). This has been associated with altered hepatic mitochondrial electron transport chain complex activity and with increased expression of genes involved in lipogenesis, oxidative stress and inflammation (Bruce et al. 2009). An effect of maternal high-fat diet on offspring liver triglyceride content has also been shown in non-human primates in which the offspring of females maintained long-term on a high-fat diet had increased liver triglyceride content and evidence of increased hepatic oxidative stress whether or not their mothers had become obese, suggesting that programming of liver fat may be independent of maternal obesity, at least in this model (McCurdy et al. 2009). The impact of maternal obesity in humans on offspring development of non-alcoholic fatty liver disease has not been studied, although preliminary evidence suggests that early feeding habits may impact on development of fatty liver disease in childhood suggesting a potential role for early life experience in development of this condition (Nobili et al. 2009).

\section{Programming of blood pressure and vascular function}

A number of rodent studies have demonstrated that the offspring of mothers maintained on a high-fat diet before and during pregnancy and through lactation develop high blood pressure (BP; Khan et al. 2003, 2005, Samuelsson et al. 2008, 2010, Elahi et al. 2009, Liang et al. 2009), which deteriorates further with age (Samuelsson et al. 2008, Liang et al. 2009). Khan et al. (2005) cross-fostered offspring of obese rat mothers onto normal controls and showed that exposure to maternal obesity/high-fat diet during gestation was sufficient to programme hypertension in the offspring. In terms of mechanisms, in rats, the offspring of obese mothers have 
endothelial dysfunction (Koukkou et al. 1998, Ghosh et al. 2001, Taylor et al. 2004, Khan et al. 2005) including reduced endothelium-dependent vasodilatation in both small and large vessels (Koukkou et al. 1998, Ghosh et al. 2001, Taylor et al. 2004, Armitage et al. 2005), altered vascular fatty acid content (Ghosh et al. 2001) and increased aortic stiffness with reduced smooth muscle cell number and endothelial cell volume (Armitage et al. 2005). Very recent studies using a rodent model of programming by maternal obesity have demonstrated that the offspring of obese females develop hypertension and increased cardiovascular response to stress before the onset of increased adiposity or hyperleptinaemia, accompanied by evidence of increased sympathetic activity and increased renal norepinephrine concentration and renin expression (Samuelsson et al. 2010), suggesting that programming of autonomic function might be one mechanism underpinning the development of hypertension in this model. However, these findings are not consistent across all studies (Armitage et al. 2005), so that further studies are required to delineate the precise mechanisms of programming of hypertension in the different models.

Despite this animal evidence, there are no data in humans examining the association between maternal obesity and offspring BP. This is probably due to lack of available obese pregnancy-offspring cohorts with measurements of BP in the offspring in adulthood. However, a positive association was reported between gestational weight gain and both offspring obesity and systolic BP at the age of 3 years (Oken et al. 2007). In addition, in a population-based cohort of 2432 individuals aged 21 years, a greater gestational weight gain was associated with greater $\mathrm{BMI}$ and with increased systolic BP $(0.2 \mathrm{mmHg}$ per $0.1 \mathrm{~kg}, 95 \% \mathrm{Cl}-0.2$ to 0.6 ; Mamun et al. 2009). Although the latter was not statistically significant, the effect size was of similar magnitude as the statistically significant association with BMI. Likewise, although maternal vascular function is altered in pregnancies complicated by obesity with lower endothelium-dependent and endothelium-independent vasodilatation when compared with lean counterparts (Stewart et al. 2007), there are no studies to date examining vascular function in offspring of obese mothers.

\section{Future directions for research}

As discussed above, many studies in animal models have shown that exposure to maternal obesity/overnutrition during pregnancy $+/$ - lactation is associated with programming of cardiovascular risk in the offspring. The remarkably similar programming effects observed in the offspring, including programming of obesity and metabolic and vascular dysfunction, from different experimental paradigms and in species with different reproductive strategies suggest that identification of common mechanisms may be possible using data from current animal models and may indeed be relevant to humans.

Nevertheless, extrapolating data from extant animal studies to determine public health policy may be difficult. Studies have employed different diets, for example high-fat, 'cafeteria' and 'junk food' diets, making it difficult to draw conclusions about the potential role of particular nutrients in the programming of disease risk. Additionally, it is not always clear whether the diets employed were matched for other dietary components such as protein, since low-protein diets are well known to programme offspring metabolism (reviewed in Davenport \& Cabrero (2009)). Studies are urgently needed to dissect the role of dietary composition in the programming of offspring disease risk. Further studies should also be directed at identifying critical developmental windows of importance in the programming of disease risk to dissect not only the role of maternal obesity versus foetal overnutrition per se but also the relative importance of overnutrition during critical developmental windows within pregnancy and during lactation. Such studies are of paramount importance in informing public health policy in terms of advising women about weight management and diet prior to and during pregnancy.

One area in which there has been much recent interest is the potential role of epigenetic mechanisms in developmental programming. The term 'epigenetic modifications' is generally used to describe changes in gene function which are not explained by changes in DNA sequence and which may be mitotically and/or meiotically heritable. Epigenetic modifications that mediate this include DNA methylation, histone modifications and small non-coding RNA, and there is a growing literature demonstrating altered DNA methylation and histone modifications in animal models of intrauterine growth retardation (Waterland \& Michels 2007). More recently, the role of epigenetic modifications in mediating the effects of maternal obesity on the offspring has been investigated in several recent studies in primates, which have shown global and genespecific alterations in DNA methylation and histone modifications with maternal exposure to a high-fat diet (Agaard-Tillery et al. 2008). In humans, emerging data suggest that severe maternal undernutrition may result in persistent epigenetic changes in the offspring (Heijmans et al. 2008), but the effects of maternal obesity have not been examined.

\section{Other programming targets}

While the focus of this review has been the impact of maternal obesity on offspring obesity, body composition and cardiometabolic health, there are also other longterm adverse effects of maternal obesity on offspring health. This has been little explored in humans beyond 
childhood. However, there is emerging evidence that maternal obesity impacts on offspring brain function including cognitive function and psychiatric or mood disturbances; children of women who are overweight pre-pregnancy or gain a large amount of weight during pregnancy have a twofold risk of attention deficit hyperactivity disorder symptoms compared to normalweight women (Rodriguez et al. 2008), as well as problems with emotional regulation (Rodriguez 2010). These effects are substantial, and thus clinically relevant, if causal. Preliminary data also suggest that maternal obesity increases risk of the offspring developing asthma (Reichman \& Nepomnyaschy 2008) and eczema (Kusunoki et al. 2008) in childhood. Future studies will determine the impact of maternal obesity on a range of morbidities in the offspring, including reproductive health, and whether the effects of maternal obesity on offspring health persist into adulthood.

\section{How can we prevent the long-term consequences of maternal obesity on offspring outcome?}

Given the clear associations of maternal obesity with adverse long-term outcomes for the offspring, it would appear that interventions that result in maternal weight loss should be beneficial to the offspring and have a potentially great impact on public health. A follow-up study of 111 children from 49 obese mothers who had lost $36 \pm 1.8 \%$ body weight sustained for $12 \pm 0.8$ years with bariatric surgery (weight loss surgery) showed that the children had lower birth weight associated with reduced prevalence of macrosomia. At follow-up at the age of 2.5-26 years, the children were leaner, and had improved metabolic profiles with greater insulin sensitivity and improved lipid profile (Smith et al. 2009a). However, there remain many questions, including when is the best time for women to lose weight when planning pregnancy, and how should they manage their weight when pregnant? A recent systematic review noted that there is minimal evidence to support any specific dietary or lifestyle intervention strategy (Dodd et al. 2008), and results of randomised controlled trials are eagerly awaited.

\section{Conclusions}

Thus, a growing body of evidence from both animal and human studies suggests that maternal obesity has an impact on offspring health, which has profound implications for public health policy. Of particular concern is the increased risk of obesity and metabolic sequelae in the offspring of obese mothers reported in both animal and human studies, which has the potential to result in an 'intergenerational cycle' affecting obesity and cardiovascular disease risk across a number of generations (Drake \& Walker 2004, Drake \& Liu 2010).
Further studies are urgently needed in order to delineate the mechanisms underpinning these programming effects and identify suitable interventions to reduce the risks of these complications in the offspring.

\section{Declaration of interest}

The authors declare that there is no conflict of interest that could be perceived as prejudicing the impartiality of this review.

\section{Funding}

A J Drake is supported by a Medical Research Council Clinician Scientist Award (G05-01904). Both R M Reynolds and A J Drake's work on maternal obesity and offspring outcomes is supported by Tommy's, the baby charity, to whom we are very grateful.

\section{References}

Agaard-Tillery KM, Grove K, Bishop J, Ke X, Fu Q, McKnight R \& Lane RH 2008 Developmental origins of disease and determinants of chromatin structure: maternal diet modifies the primate fetal epigenome. Journal of Molecular Endocrinology 41 91-102.

Armitage JA, Lakasing L, Taylor PD, Balachandran AA, Jensen RI, Dekou V, Ashton N, Nyengaard JR \& Poston L 2005 Developmental programming of aortic and renal structure in offspring of rats fed fat-rich diets in pregnancy. Journal of Physiology 565 171-184.

Armitage JA, Poston L \& Taylor PD 2008 Developmental origins of obesity and the metabolic syndrome: the role of maternal obesity. Frontiers of Hormone Research 36 73-84.

Bayol SA, Simbi BH \& Stickland NC 2005 A maternal cafeteria diet during gestation and lactation promotes adiposity and impairs skeletal muscle development and metabolism in rat offspring at weaning. Journal of Physiology 567 951-961.

Bayol SA, Farrington SJ \& Stickland NC 2007 A maternal 'junk food' diet in pregnancy and lactation promotes an exacerbated taste for 'junk food' and a greater propensity for obesity in rat offspring. British Journal of Nutrition 98 843-851.

Bayol SA, Simbi BH, Bertrand JA \& Stickland NC 2008 Offspring from mothers fed a 'junk food' diet in pregnancy and lactation exhibit exacerbated adiposity that is more pronounced in females. Journal of Physiology 586 3219-3230.

Bayol SA, Macharia R, Farrington SJ, Simbi BH \& Stickland NC 2009 Evidence that a maternal "junk food" diet during pregnancy and lactation can reduce muscle force in offspring. European Journal of Nutrition 48 62-65.

Blair NJ, Thompson JM, Black PN, Becroft DM, Clark PM, Han DY, Robinson E, Waldie KE, Wild CJ \& Mitchell EA 2007 Risk factors for obesity in 7-year-old European children: the Auckland Birthweight Collaborative Study. Archives of Disease in Childhood 92 866-871.

Boney CM, Verma A, Tucker R \& Vohr BR 2005 Metabolic syndrome in childhood: association with birth weight, maternal obesity, and gestational diabetes mellitus. Pediatrics 115 e290-e296.

Bruce KD, Cagampang FR, Argenton M, Zhang J, Ethirajan PL, Burdge GC, Bateman AC, Clough GF, Poston L, Hanson MA et al. 2009 Maternal high-fat feeding primes steatohepatitis in adult mice offspring, involving mitochondrial dysfunction and altered lipogenesis gene expression. Hepatology 50 1796-1808.

Buckley AJ, Keseru B, Briody J, Thompson M, Ozanne SE \& Thompson CH 2005 Altered body composition and metabolism in the male offspring of high fat-fed rats. Metabolism 54 500-507.

Burdette HL, Whitaker RC, Hall WC \& Daniels SR 2006 Maternal infantfeeding style and children's adiposity at 5 years of age. Archives of Pediatrics \& Adolescent Medicine 160 513-520. 
Caluwaerts S, Lambin S, van Bree R, Peeters H, Vergote I \& Verhaeghe J 2007 Diet-induced obesity in gravid rats engenders early hyperadiposity in the offspring. Metabolism 56 1431-1438.

Carpenter MW, Canick JA, Star J, Carr SR, Burke ME \& Shahinian K 1996 Fetal hyperinsulinism at 14-20 weeks and subsequent gestational diabetes. Obstetrics and Gynecology 87 89-93.

Catalano PM, Drago NM \& Amini SB 1995 Maternal carbohydrate metabolism and its relationship to fetal growth and body composition. American Journal of Obstetrics and Gynecology 172 1464-1470.

Catalano PM, Presley L, Minium J \& Hauguel-de MS 2009 Fetuses of obese mothers develop insulin resistance in utero. Diabetes Care 32 1076-1080.

Chang GQ, Gaysinskaya V, Karatayev O \& Leibowitz SF 2008 Maternal high-fat diet and fetal programming: increased proliferation of hypothalamic peptide-producing neurons that increase risk for overeating and obesity. Journal of Neuroscience 28 12107-12119.

Davenport MH \& Cabrero MR 2009 Maternal nutritional history predicts obesity in adult offspring independent of postnatal diet. Journal of Physiology 587 3423-3424.

Davidowa H \& Plagemann A 2000 Different responses of ventromedial hypothalamic neurons to leptin in normal and early postnatally overfed rats. Neuroscience Letters 293 21-24.

Dodd JM, Crowther CA \& Robinson JS 2008 Dietary and lifestyle interventions to limit weight gain during pregnancy for obese or overweight women: a systematic review. Acta Obstetricia et Gynecologica Scandinavica 87 702-706.

Drake AJ \& Liu L 2010 Intergenerational transmission of programmed effects: public health consequences. Trends in Endocrinology and Metabolism 21 206-213.

Drake AJ \& Walker BR 2004 The intergenerational effects of fetal programming: non-genomic mechanisms for the inheritance of low birth weight and cardiovascular risk. Journal of Endocrinology 180 1-16.

Elahi MM, Cagampang FR, Mukhtar D, Anthony FW, Ohri SK \& Hanson MA 2009 Long-term maternal high-fat feeding from weaning through pregnancy and lactation predisposes offspring to hypertension, raised plasma lipids and fatty liver in mice. British Journal of Nutrition 102 514-519.

Ford SP, Zhang L, Zhu M, Miller MM, Smith DT, Hess BW, Moss GE, Nathanielsz PW \& Nijland MJ 2009 Maternal obesity accelerates fetal pancreatic $\beta$-cell but not $\alpha$-cell development in sheep: prenatal consequences. American Journal of Physiology. Regulatory, Integrative and Comparative Physiology 297 R835-R843.

Gale CR, Javaid MK, Robinson SM, Law CM, Godfrey KM \& Cooper C 2007 Maternal size in pregnancy and body composition in children. Journal of Clinical Endocrinology and Metabolism 92 3904-3911.

Ghosh P, Bitsanis D, Ghebremeskel K, Crawford MA \& Poston L 2001 Abnormal aortic fatty acid composition and small artery function in offspring of rats fed a high fat diet in pregnancy. Journal of Physiology 533 815-822.

Guo F \& Jen KL 1995 High-fat feeding during pregnancy and lactation affects offspring metabolism in rats. Physiology and Behavior 57 681-686.

Gupta A, Srinivasan M, Thamadilok S \& Patel MS 2009 Hypothalamic alterations in fetuses of high fat diet-fed obese female rats. Journal of Endocrinology 200 293-300.

Harvey NC, Poole JR, Javaid MK, Dennison EM, Robinson S, Inskip HM, Godfrey KM, Cooper C \& Sayer AA 2007 Parental determinants of neonatal body composition. Journal of Clinical Endocrinology and Metabolism 92 523-526.

Heijmans BT, Tobi EW, Stein AD, Putter H, Blauw GJ, Susser ES, Slagboom PE \& Lumey LH 2008 Persistent epigenetic differences associated with prenatal exposure to famine in humans. PNAS 105 17046-17049.

Heslehurst N, Ells LJ, Simpson H, Batterham A, Wilkinson J \& Summerbell CD 2007 Trends in maternal obesity incidence rates, demographic predictors, and health inequalities in 36,821 women over a 15-year period. British Journal of Obstetrics and Gynaecology 114 187-194.

Howie GJ, Sloboda DM, Kamal T \& Vickers MH 2009 Maternal nutritional history predicts obesity in adult offspring independent of postnatal diet. Journal of Physiology 587 905-915.
Hull HR, Dinger MK, Knehans AW, Thompson DM \& Fields DA 2008 Impact of maternal body mass index on neonate birthweight and body composition. American Journal of Obstetrics and Gynecology 198416.

Jensen DM, Damm P, Sorensen B, Molsted-Pedersen L, Westergaard JG, Ovesen P \& Beck-Nielsen H 2003 Pregnancy outcome and prepregnancy body mass index in 2459 glucose-tolerant Danish women. American Journal of Obstetrics and Gynecology 189 239-244.

Kanagalingam MG, Forouhi NG, Greer IA \& Sattar N 2005 Changes in booking body mass index over a decade: retrospective analysis from a Glasgow Maternity Hospital. British Journal of Obstetrics and Gynaecology 112 1431-1433.

Khan IY, Taylor PD, Dekou V, Seed PT, Lakasing L, Graham D, Dominiczak AF, Hanson MA \& Poston L 2003 Gender-linked hypertension in offspring of lard-fed pregnant rats. Hypertension 41 $168-175$

Khan I, Dekou V, Hanson M, Poston L \& Taylor P 2004 Predictive adaptive responses to maternal high-fat diet prevent endothelial dysfunction but not hypertension in adult rat offspring. Circulation 110 1097-1102.

Khan IY, Dekou V, Douglas G, Jensen R, Hanson MA, Poston L \& Taylor PD 2005 A high-fat diet during rat pregnancy or suckling induces cardiovascular dysfunction in adult offspring. American Journal of Physiology. Regulatory, Integrative and Comparative Physiology 288 R127-R133.

Kim J, Peterson KE, Scanlon KS, Fitzmaurice GM, Must A, Oken E, Rifas-Shiman SL, Rich-Edwards JW \& Gillman MW 2006 Trends in overweight from 1980 through 2001 among preschool-aged children enrolled in a health maintenance organization. Obesity 14 1107-1112.

Koukkou E, Ghosh P, Lowy C \& Poston L 1998 Offspring of normal and diabetic rats fed saturated fat in pregnancy demonstrate vascular dysfunction. Circulation 98 2899-2904.

Koupil I \& Toivanen P 2008 Social and early-life determinants of overweight and obesity in 18-year-old Swedish men. International Journal of Obesity 32 73-81.

Kusunoki T, Morimoto T, Nishikomori R, Heike T, Ito $M$, Hosoi S \& Nakahata T 2008 Obesity and the prevalence of allergic diseases in schoolchildren. Pediatric Allergy and Immunology 19 527-534.

Laitinen J, Power C \& Jarvelin MR 2001 Family social class, maternal body mass index, childhood body mass index, and age at menarche as predictors of adult obesity. American Journal of Clinical Nutrition $\mathbf{7 4}$ 287-294.

Lawlor DA, Smith GD, O'Callaghan M, Alati R, Mamun AA, Williams GM \& Najman JM 2007 Epidemiologic evidence for the fetal overnutrition hypothesis: findings from the Mater-University study of pregnancy and its outcomes. American Journal of Epidemiology 165 418-424.

Lawlor DA, Timpson NJ, Harbord RM, Leary S, Ness A, McCarthy MI, Frayling TM, Hattersley AT \& Smith GD 2008 Exploring the developmental overnutrition hypothesis using parental-offspring associations and FTO as an instrumental variable. PLoS Medicine 5 e33.

Lazarin MA, Bennini JR, Pereira CL, Astiarraga BD, Ferrannini E \& Muscelli E 2004 Normal insulin sensitivity in lean offspring of obese parents. Obesity Research 12 621-626.

Levin BE \& Govek E 1998 Gestational obesity accentuates obesity in obesityprone progeny. American Journal of Physiology 275 R1374-R1379.

Lewis DS, Bertrand HA, McMahan CA, McGill HC Jr, Carey KD \& Masoro EJ 1986 Preweaning food intake influences the adiposity of young adult baboons. Journal of Clinical Investigation 78 899-905.

Li Y, Plagemann A \& Davidowa H 2002 Increased inhibition by agouti-related peptide of ventromedial hypothalamic neurons in rats overweight due to early postnatal overfeeding. Neuroscience Letters 330 33-36.

Li C, Kaur H, Choi WS, Huang TT, Lee RE \& Ahluwalia JS 2005 Additive interactions of maternal prepregnancy BMI and breast-feeding on childhood overweight. Obesity Research 13 362-371.

Liang C, Oest ME \& Prater MR 2009 Intrauterine exposure to high saturated fat diet elevates risk of adult-onset chronic diseases in C57BL/6 mice. Birth Defects Research. Part B, Developmental and Reproductive Toxicology 86 377-384.

Magee TR, Han G, Cherian B, Khorram O, Ross MG \& Desai M 2008 Down-regulation of transcription factor peroxisome proliferatoractivated receptor in programmed hepatic lipid dysregulation and inflammation in intrauterine growth-restricted offspring. American Journal of Obstetrics and Gynecology 199 271-275. 
Mamun AA, O'Callaghan M, Callaway L, Williams G, Najman J \& Lawlor DA 2009 Associations of gestational weight gain with offspring body mass index and blood pressure at 21 years of age: evidence from a birth cohort study. Circulation 119 1720-1727.

McCurdy CE, Bishop JM, Williams SM, Grayson BE, Smith MS, Friedman JE \& Grove KL 2009 Maternal high-fat diet triggers lipotoxicity in the fetal livers of nonhuman primates. Journal of Clinical Investigation 119 323-335.

McIntyre \& HAPO Study Cooperative Research Group 2010 Hyperglycaemia and Adverse Pregnancy Outcome (HAPO) Study: associations with maternal body mass index. British Journal of Obstetrics and Gynaecology 117 575-584.

McMillen IC, Adam CL \& Muhlhausler BS 2005 Early origins of obesity: programming the appetite regulatory system. Journal of Physiology 565 9-17.

Mesman I, Roseboom TJ, Bonsel GJ, Gemke RJ, van der Wal MF \& Vrijkotte TG 2009 Maternal pre-pregnancy body mass index explains infant's weight and BMI at 14 months: results from a multi-ethnic birth cohort study. Archives of Disease in Childhood 94 587-595.

Minge CE, Bennett BD, Norman RJ \& Robker RL 2008 Peroxisome proliferator-activated receptor- $\gamma$ agonist rosiglitazone reverses the adverse effects of diet-induced obesity on oocyte quality. Endocrinology 149 2646-2656.

Mingrone G, Manco M, Mora ME, Guidone C, laconelli A, Gniuli D, Leccesi L, Chiellini C \& Ghirlanda G 2008 Influence of maternal obesity on insulin sensitivity and secretion in offspring. Diabetes Care $\mathbf{3 1}$ 1872-1876.

Muhlhausler BS, Adam CL, Marrocco EM, Findlay PA, Roberts CT, McFarlane JR, Kauter KG \& McMillen IC 2005 Impact of glucose infusion on the structural and functional characteristics of adipose tissue and on hypothalamic gene expression for appetite regulatory neuropeptides in the sheep fetus during late gestation. Journal of Physiology 565 185-195.

Muhlhausler BS, Duffield JA \& McMillen IC 2007 Increased maternal nutrition stimulates peroxisome proliferator activated receptor- $\gamma$, adiponectin, and leptin messenger ribonucleic acid expression in adipose tissue before birth. Endocrinology 148 878-885

Nivoit P, Morens C, Van Assche FA, Jansen E, Poston L, Remacle C \& Reusens B 2009 Established diet-induced obesity in female rats leads to offspring hyperphagia, adiposity and insulin resistance. Diabetologia $\mathbf{5 2}$ 1133-1142.

Nobili V, Bedogni G, Alisi A, Pietrobattista A, Alterio A, Tiribelli C \& Agostoni C 2009 A protective effect of breastfeeding on the progression of non-alcoholic fatty liver disease. Archives of Disease in Childhood 94 801-805.

Oddy WH, Li J, Landsborough L, Kendall GE, Henderson S \& Downie J 2006 The association of maternal overweight and obesity with breastfeeding duration. Journal of Pediatrics 149 185-191.

Ogden CL, Carroll MD, Curtin LR, McDowell MA, Tabak CJ \& Flegal KM 2006 Prevalence of overweight and obesity in the United States, 1999-2004. Journal of the American Medical Association 295 1549-1555.

Oken E, Taveras EM, Kleinman KP, Rich-Edwards JW \& Gillman MW 2007 Gestational weight gain and child adiposity at age 3 years. American Journal of Obstetrics and Gynecology 196 322-328.

Oken E, Rifas-Shiman SL, Field AE, Frazier AL \& Gillman MW 2008 Maternal gestational weight gain and offspring weight in adolescence. Obstetrics and Gynecology 112 999-1006.

Olson CM, Strawderman MS \& Dennison BA 2009 Maternal weight gain during pregnancy and child weight at age 3 years. Maternal and Child Health Journal 13 839-846.

Parsons TJ, Power C, Logan S \& Summerbell CD 1999 Childhood predictors of adult obesity: a systematic review. International Journal of Obesity and Related Metabolic Disorders 23 (Supplement 8) S1-S107.

Plagemann A, Heidrich I, Gotz F, Rohde W \& Dorner G 1992 Obesity and enhanced diabetes and cardiovascular risk in adult rats due to early postnatal overfeeding. Experimental and Clinical Endocrinology 99 154-158.

Rajasingam D, Seed PT, Briley AL, Shennan AH \& Poston L 2009 A prospective study of pregnancy outcome and biomarkers of oxidative stress in nulliparous obese women. American Journal of Obstetrics and Gynecology 200 395-399.
Reichman NE \& Nepomnyaschy L 2008 Maternal pre-pregnancy obesity and diagnosis of asthma in offspring at age 3 years. Maternal and Child Health Journal 12 725-733.

Reilly JJ, Armstrong J, Dorosty AR, Emmett PM, Ness A, Rogers I, Steer C \& Sherriff A 2005 Early life risk factors for obesity in childhood: cohort study. BMJ 3301357.

Reynolds RM, Shiell AW, Osmond C, Phillips DIW \& Godfrey KM 2009 Maternal influences on offspring obesity in young adulthood: effects of BMI, parity and pregnancy weight gain. Journal of Developmental Origins of Health and Disease 1 (Supplement S1) S61-S337. Abstract P-3B-83.

Rodriguez A 2010 Maternal pre-pregnancy obesity and risk for inattention and negative emotionality in children. Journal of Child Psychology and Psychiatry 51 134-143.

Rodriguez A, Miettunen J, Henriksen TB, Olsen J, Obel C, Taanila A, Ebeling H, Linnet KM, Moilanen I \& Jarvelin MR 2008 Maternal adiposity prior to pregnancy is associated with ADHD symptoms in offspring: evidence from three prospective pregnancy cohorts. International Journal of Obesity 32 550-557.

Salsberry PJ \& Reagan PB 2005 Dynamics of early childhood overweight. Pediatrics 116 1329-1338.

Samuelsson AM, Matthews PA, Argenton M, Christie MR, McConnell JM, Jansen EH, Piersma AH, Ozanne SE, Twinn DF, Remacle C et al. 2008 Diet-induced obesity in female mice leads to offspring hyperphagia, adiposity, hypertension, and insulin resistance: a novel murine model of developmental programming. Hypertension $\mathbf{5 1}$ 383-392.

Samuelsson AM, Morris A, Igosheva N, Kirk SL, Pombo JM, Coen CW, Poston L \& Taylor PD 2010 Evidence for sympathetic origins of hypertension in juvenile offspring of obese rats. Hypertension $\mathbf{5 5}$ $76-82$.

Schaefer-Graf UM, Graf K, Kulbacka I, Kjos SL, Dudenhausen J, Vetter K \& Herrera E 2008 Maternal lipids as strong determinants of fetal environment and growth in pregnancies with gestational diabetes mellitus. Diabetes Care 31 1858-1863.

Seckl JR 2001 Glucocorticoid programming of the fetus; adult phenotypes and molecular mechanisms. Molecular and Cellular Endocrinology 185 $61-71$.

Sewell MF, Huston-Presley L, Super DM \& Catalano P 2006 Increased neonatal fat mass, not lean body mass, is associated with maternal obesity. American Journal of Obstetrics and Gynecology 195 1100-1103.

Sewell MF, Huston-Presley L, Amini SB \& Catalano PM 2007 Body mass index: a true indicator of body fat in obese gravidas. Journal of Reproductive Medicine 52 907-911.

Shankar K, Harrell A, Liu X, Gilchrist JM, Ronis MJ \& Badger TM 2008 Maternal obesity at conception programs obesity in the offspring. American Journal of Physiology. Regulatory, Integrative and Comparative Physiology 294 R528-R538.

Shelley P, Martin-Gronert MS, Rowlerson A, Poston L, Heales SJ, Hargreaves IP, McConnell JM, Ozanne SE \& Fernandez-Twinn DS 2009 Altered skeletal muscle insulin signaling and mitochondrial complex II-III linked activity in adult offspring of obese mice. American Journal of Physiology. Regulatory, Integrative and Comparative Physiology 297 R675-R681.

Shields BM, Knight BA, Powell RJ, Hattersley AT \& Wright DE 2006 Assessing newborn body composition using principal components analysis: differences in the determinants of fat and skeletal size. $B M C$ Pediatrics 624.

Smith J, Cianflone K, Biron S, Hould FS, Lebel S, Marceau S, Lescelleur O, Biertho L, Simard S, Kral JG et al. 2009a Effects of maternal surgical weight loss in mothers on intergenerational transmission of obesity. Journal of Clinical Endocrinology and Metabolism 94 4275-4283.

Smith NA, McAuliffe FM, Quinn K, Lonergan P \& Evans AC $2009 \mathrm{~b}$ Transient high glycaemic intake in the last trimester of pregnancy increases offspring birthweight and postnatal growth rate in sheep: a randomised control trial. British Journal of Obstetrics and Gynaecology 116 975-983.

Srinivasan M, Dodds C, Ghanim H, Gao T, Ross PJ, Browne RW, Dandona P \& Patel MS 2008 Maternal obesity and fetal programming: effects of a high-carbohydrate nutritional modification in the immediate postnatal life of female rats. American Journal of Physiology. Endocrinology and Metabolism 295 E895-E903. 
Stewart FM, Freeman DJ, Ramsay JE, Greer IA, Caslake M \& Ferrell WR 2007 Longitudinal assessment of maternal endothelial function and markers of inflammation and placental function throughout pregnancy in lean and obese mothers. Journal of Clinical Endocrinology and Metabolism 92 969-975.

Stuebe AM, Forman MR \& Michels KB 2009 Maternal-recalled gestational weight gain, pre-pregnancy body mass index, and obesity in the daughter. International Journal of Obesity 33 743-752.

Surkan PJ, Hsieh CC, Johansson AL, Dickman PW \& Cnattingius S 2004 Reasons for increasing trends in large for gestational age births. Obstetrics and Gynecology 104 720-726.

Tamashiro KL, Terrillion CE, Hyun J, Koenig JI \& Moran TH 2009 Prenatal stress or high-fat diet increases susceptibility to diet-induced obesity in rat offspring. Diabetes 58 1116-1125.

Taylor PD \& Poston L 2007 Developmental programming of obesity in mammals. Experimental Physiology 92 287-298.

Taylor PD, Khan IY, Hanson MA \& Poston L 2004 Impaired EDHF-mediated vasodilatation in adult offspring of rats exposed to a fat-rich diet in pregnancy. Journal of Physiology 558 943-951.

Taylor PD, McConnell J, Khan IY, Holemans K, Lawrence KM, Asare-Anane H, Persaud SJ, Jones PM, Petrie L, Hanson MA et al. 2005 Impaired glucose homeostasis and mitochondrial abnormalities in offspring of rats fed a fat-rich diet in pregnancy. American Journal of Physiology. Regulatory, Integrative and Comparative Physiology 288 R134-R139.

Tequeanes AL, Gigante DP, Assuncao MC, Chica DA \& Horta BL 2009 Maternal anthropometry is associated with the body mass index and waist:height ratio of offspring at 23 years of age. Journal of Nutrition 139 750-754.
Tong JF, Yan X, Zhu MJ, Ford SP, Nathanielsz PW \& Du M 2009 Maternal obesity downregulates myogenesis and $\beta$-catenin signaling in fetal skeletal muscle. American Journal of Physiology. Endocrinology and Metabolism 296 E917-E924.

Waterland RA \& Michels KB 2007 Epigenetic epidemiology of the developmental origins hypothesis. Annual Review of Nutrition 27 363-388.

Whitaker RC 2004 Predicting preschooler obesity at birth: the role of maternal obesity in early pregnancy. Pediatrics 114 e29-e36.

White CL, Purpera MN \& Morrison CD 2009 Maternal obesity is necessary for programming effect of high-fat diet on offspring. American Journal of Physiology. Regulatory, Integrative and Comparative Physiology 296 R1464-R1472.

Yan X, Zhu MJ, Xu W, Tong JF, Ford SP, Nathanielsz PW \& Du M 2010 Up-regulation of Toll-like receptor $4 /$ nuclear factor- $\kappa \mathrm{B}$ signaling is associated with enhanced adipogenesis and insulin resistance in fetal skeletal muscle of obese sheep at late gestation. Endocrinology 151 380-387.

Zhu MJ, Han B, Tong J, Ma C, Kimzey JM, Underwood KR, Xiao Y, Hess BW, Ford SP, Nathanielsz PW et al. 2008 AMP-activated protein kinase signalling pathways are down regulated and skeletal muscle development impaired in fetuses of obese, over-nourished sheep. Journal of Physiology 586 2651-2664.

Received 8 February 2010

First decision 15 March 2010

Revised manuscript received 17 May 2010

Accepted 18 June 2010 